\title{
Usabilidade e Interatividade em Sistemas Web para
}

\section{Cursos Online}

Rejane Cunha Freitas

Departamento de Ciências Exatas e da Terra, Campus I, Universidade do Estado da Bahia - UNEB, 41195-001 -

Salvador - BA - Brasil.

Faculdade Integrada do Ceará - FIC, 60125160 -

Fortaleza - CE - Brasil.

rfreitas@uneb.br; rejanecf@fic.br

\author{
Marlene de Alencar Dutra \\ Departamento de Educação, Campus XIII, Universidade \\ do Estado da Bahia - UNEB, 46880-000 - Itaberaba - BA \\ - Brasil. \\ marnena@gmail.com
}

Resumo Este artigo descreve a pesquisa realizada para avaliar a usabilidade de sistemas Web para ensino a distância. No intuito de identificar os problemas de usabilidade e suas possiveis consequências para as interações nos ambientes virtuais de aprendizagem. Inicialmente foi construído um referencial teórico abordando conceitos de interação humano-computador, usabilidade e interatividade. Em seguida a investigação foi conduzida através de testes com os usuários, que por meio de questionários opinarem sobre os ambientes virtuais de aprendizagem WebAula e Moodle. Os resultados indicaram problemas de usabilidade relacionados com a navegação, links, nome de categorias, pop-ups e procura nestes sistemas. A partir da hipótese de que tais problemas impedem uma maior e melhor utilização pelos usuários dos sistemas Web para cursos online, foram feitas reflexões sobre a usabilidade e a interatividade nos ambientes em estudo.

Palavras-Chave: Interatividade, Usabilidade, Ambientes Virtuais de Aprendizagem.

\begin{abstract}
This paper describes the research done for evaluating the usability of Web systems for distance learning, with the goal of identifying usability problems and their consequences for the interactions with these virtual learning environments. First, it was built a theoretic foundation addressing human-computer interfaces, usability and interactivity. Then, the investigation was conducted through tests with the users, which answered questionnaires for evaluation of two learning environments Moodle and WebAula. The results indicated usability problems with navigation, links, category names, pop-ups and searching in these systems. Assuming the hypothesis that such problems difficult a wider and better utilization of Web systems for on-line courses by the users, reflections were made about the usability and interactivity of the environments under study.
\end{abstract}

Keywords: Interactivity, Usability, Virtual Environments of Learning. 


\section{Introdução}

O termo usabilidade faz parte do vocabulário técnico da Ciência da Computação, na área de Interação HumanoComputador (IHC), se refere à qualidade da interação entre sistemas e usuários e depende de vários aspectos, como a facilidade em aprender, a eficiência, a satisfação do usuário, para citar alguns. Pesquisas são realizadas há mais de 20 anos nesta área, elas tratam principalmente de técnicas de avaliação de usabilidade, que demonstram tanto os resultados do emprego destas técnicas, como a medida da eficiência das mesmas. Desta forma, com a validação e qualificação dos processos de avaliação, busca-se a identificação dos principais problemas de usabilidade de sistemas e a indicação de como tratá-los.

Neste contexto, destaca-se o Nielsen Norman Group ${ }^{1}$ que realiza testes para avaliar a usabilidade de sistemas Web desde 1994. Publicações recentes [12] do grupo apontam que os usuários desses sistemas estão menos tolerantes, pois de uma forma geral têm menos barreiras e atrasos na obtenção do que querem na Web. Isto, em parte por causa dos sites de busca, que oferecem uma lista de endereços que podem resolver o problema do usuário. Em parte também, porque o acesso a páginas Web é algo rotineiro e o número de sites e páginas disponíveis aumentou. Por isso, pensar a usabilidade de sistemas Web comerciais é importante, este atributo de qualidade pode cativar ou afastar usuários, que neste caso, são clientes em potencial.

De forma semelhante, estudos sobre a usabilidade em sistemas Web para cursos online são relevantes, na medida em que contribuem para facilitar as tarefas de manipulação por parte dos usuários. Por isso, a necessidade de conduzir testes com os estudantes, professores, administradores dos ambientes, equipe de produção de material, dentre outros que utilizam tais sistemas, para que possam apontar preferências quanto ao design, as funcionalidades e a interatividade do sistema e também se eles facilitam ou confundem os participantes de um curso online.

Além disso, torna-se necessário validar critérios capazes de avaliar a usabilidade levando em conta esse contexto de uso. A hipótese é que, se o sistema está relacionado à educação a distância $(\mathrm{EaD})$, a preocupação é se o mesmo suporta de forma fácil e eficiente a execução de tarefas com objetivos pedagógicos. Neste caso, os critérios de avaliação da usabilidade, já sedimentados na área podem, ou não, corroborar neste sentido.

Para melhor compreender a usabilidade neste cenário

1

www.nngroup.com/ da EaD buscou-se também fundamentação no conceito de interatividade. $\mathrm{O}$ qual foi tomado aqui em sua acepção relacionada à expressão comunicacional que permite aos atores/autores de um curso online participação e intervenção ativa, de forma que todos tenham possibilidade de atuar, contribuir, e se for o caso, modificar o processo de desenvolvimento do curso. Deste modo, não somente um conceito de informática e sim, como co-autoria da comunicação pessoa-pessoa, pessoatecnologias da informação e da comunicação e pessoapessoa conectadas por estas tecnologias [20].

Portanto, o objetivo deste trabalho foi avaliar a usabilidade em ambientes virtuais de aprendizagem (AVA) levando em conta critérios, originalmente criados para sistemas Web comerciais, com a intenção de investigar sua aplicabilidade. Além disso, para a análise dos dados foram mapeadas categorias observáveis nos ambientes que favoreciam a interatividade. Por exemplo, na execução de tarefas características dos cursos online.

Através da realização de testes com usuários foram avaliados dois ambientes de aprendizagem virtual, o WebAula $^{2}$ e o Moodle $^{3}$. Os usuários, neste caso, eram estudantes do segundo semestre de cursos de graduação tecnológica presencial de uma instituição de ensino superior, os quais cursavam uma disciplina a distância e utilizavam os ambientes em questão.

Os resultados indicaram problemas relacionados com a navegação, links, nome de categorias, pop-ups e procura, apontados pelos usuários na avaliação dos sistemas Moodle e WebAula.

Este artigo encontra-se dividido nas seguintes partes: um breve referencial teórico sobre a usabilidade de sistemas e a interatividade em cursos online, e a avaliação de usabilidade de sistemas Web para fins educacionais, seguida da descrição da metodologia utilizada, da apresentação e da análise dos resultados.

\section{Interação Humano-Computador}

Para a Association for Computing Machinery Special Interest Group on Computer-Human Interaction - ACM SIGCHI [1], a IHC é uma área que abrange a concepção, avaliação e implementação de sistemas computacionais interativos, para uso humano, e o estudo das principais questões relacionadas a estes sistemas. Assim, a IHC tem por objetivo fornecer aos pesquisadores $\mathrm{e}$ desenvolvedores de sistemas explicações e previsões para fenômenos da interação usuário-sistema. Com resultados

2 http://www.webaula.com.br/

3 http://moodle.org/ 
práticos que possibilitam antecipadamente determinar se o design e a interface do sistema satisfazem as necessidades de usabilidade, aplicabilidade e comunicabilidade dos usuários.

Nielsen [11] apresenta um conceito relacionado à IHC, o de aceitabilidade do sistema, como uma combinação da aceitabilidade social - que diz respeito principalmente aos benefícios ou "incômodos" sociais que o software pode prover aos seus usuários, por exemplo, os sistemas de controle das portas de entrada em bancos, que apesar de benéficos, não são aceitos socialmente, pois dificultam a entrada das pessoas no banco; e da aceitabilidade prática - que refere-se às qualidades técnicas do software, como confiabilidade, custo, compatibilidade, e também a utilidade e a usabilidade do sistema. Essa classificação é mostrada na figura 1.

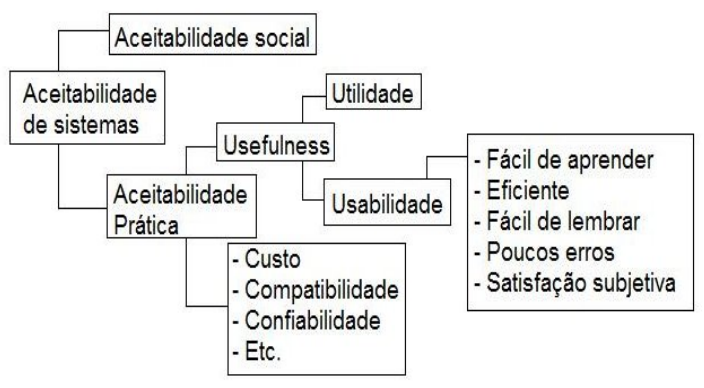

Figura 1. Atributos de Aceitabilidade de Sistemas [16].

Ao comentar o conceito de utilidade, Nielsen exemplifica que um "software educativo tem alta utilidade se os estudantes aprendem ao utilizá-lo, e um produto de entretenimento tem alta utilidade se usá-lo é divertido" [11].

Tanto a aceitabilidade social, como as subclassificações da aceitabilidade prática são categorias tratadas pela IHC, o que implica em certo grau de complexidade atender aos requisitos de todas elas. Como afirma Rocha e Baranauskas [16]:

[...] a pesquisa de IHC é fundada na crença de que o centro e ponto básico de análise são as pessoas usando um sistema computacional. Suas necessidades, capacidades e preferências para executar diversas tarefas devem informar os meios como os sistemas devem ser projetados e implantados. As pessoas não devem ter que mudar radicalmente para se adequar ao sistema, o sistema sim deve ser projetado para se adequar aos seus requisitos (p.18).

Entretanto, esta não é uma tarefa fácil, como afirma Bastien e Scapin [3], pois se trata de 'uma qualidade psicológica'. Esta é uma "tarefa que envolve vários domínios do comportamento humano, correspondentes aos diversos processos mentais de tratamento da informação (percepção, raciocínios, representação mental) que são de domínio da ergonomia ${ }^{4}$ cognitiva" [19]. Além disso, como essa área de estudo procura conhecer o usuário, pesquisas são conduzidas para identificar os perfis e as preferências destes, que pode tratar se de um público alvo bem específico. Mas, também, pode tratar se de grupos diversos e heterogêneos, o que torna a tarefa complexa.

Especificamente, em relação aos ambientes virtuais de aprendizagem, avaliar no mais amplo sentido, sua aceitabilidade, também não é tarefa fácil, porque a concepção e implementação destes ambientes atendem a requisitos diversos, dentre eles:

(i) uma epistemologia educacional que reflete as concepções teóricas sobre a aprendizagem, e norteiam o processo ensino-aprendizagem;

(ii) situações didáticas pensadas e construídas por equipes multidisciplinares;

(iii) disponibilidade de recursos técnicos para os perfis diversificados de usuários.

Por isso, a necessidade de um direcionamento neste estudo, para a usabilidade como aspecto técnico de qualidade dos AVA, quando utilizados por estudantes de cursos de graduação. E a interatividade como aspecto pedagógico, ancorado na perspectiva construtivista interacionista de Piaget [14] e na taxonomia do termo defendida por Primo e Cassol [15] e Silva [20]. Contudo, a análise teve como foco a execução de tarefas no ambientes, como obtenção de recursos e postagem de mensagens no fórum, não foi objeto de analise aqui o material didático. Apesar de compreender a importância destes aspectos na validação dos AVA como ferramentas auxiliares na construção de conhecimentos, a partir das relações sociais, da bidirecionalidade, do trabalho cooperativo, e dos conteúdos que emergem durante a relação, tais restrições foram necessárias no intuito de delimitar o estudo.

\subsection{Usabilidade}

A partir da contextualização da IHC e da avaliação dos ambientes virtuais de aprendizagem, chega-se ao conceito de usabilidade em sistemas Web para cursos

4 "É o conjunto de conhecimentos a respeito do homem em atividade, a fim de aplicá-los à concepção das tarefas, dos instrumentos, das máquinas e dos sistemas de produção" [8 apud 19]. 
online. Tomando como ponto de partida os aspectos que contribuem para a qualidade da interação entre sistemas e usuários (mostrados na figura 1) segundo Nielsen [11]:

- facilidade de aprendizagem: refere-se ao tempo e esforço necessários para que os usuários atinjam um determinado nível de familiaridade;

- facilidade de utilização (eficiência): refere-se a usuários com certa experiência e avalia o esforço físico e cognitivo dos mesmos durante o processo de interação, medindo a velocidade e o número de erros cometidos durante a execução de uma determinada tarefa;

- facilidade de relembrar: refere-se a possibilita do usuário que fica algum tempo sem interagir com o sistema, de quando voltar a utilizá-lo, lembrar-se das principais ações, sem consultar manuais;

- geração de poucos erros: pressupõe um processo de desenvolvimento que minimize a ocorrência de erro. Portanto, é importante que o sistema possua mensagens de erro consistentes, que informem ao usuário onde está o erro e como corrigi-lo;

- satisfação subjetiva dos usuários: está relacionada às funcionalidades oferecidas pelo sistema ao usuário. Relevante, em especial, quando se considera sistemas usados fora do ambiente de trabalho, tais como jogos, sistemas domésticos em geral, dentre outros.

Cada uma das características apresentadas refere-se a um aspecto que deve ser tratado com cuidado durante o design de um sistema e sua aplicabilidade depende da qualidade do processo de desenvolvimento de sistemas.

Os problemas de usabilidade classificam-se conforme a experiência do usuário e o tipo de tarefa que afetam, no contexto de uso do sistema. Para identificação destes problemas a avaliação da usabilidade pode ser feita em qualquer fase do processo de desenvolvimento, mas para evitar grandes mudanças, sugere-se que seja feita antes da finalização do processo [5]. Desta forma, para obtenção de boa usabilidade podem ser adotados o design centrado no usuário, técnicas de interação adequadas aos usuários, tarefas e contexto, tecnologias de interface apropriadas e métodos de avaliação de usabilidade.

Para avaliação da usabilidade os principais métodos utilizados são: os métodos analíticos, que não contam com a participação direta dos usuários, são realizados por especialistas em usabilidade e baseiam-se em regras, recomendações e princípios; e os testes com a participação direta do usuário, seja através de questionários e entrevistas, ou ainda, pela observação controlada do uso do sistema.

Para avaliação através de um método analítico, Dias [5] sugere para a avaliação heurística um conjunto de sete princípios gerais de usabilidade que podem ser aplicadas a sistemas Web comerciais. Essas heurísticas são propostas pela autora como uma compilação de estudos práticos de vários pesquisadores, Nielsen [11], Bastien e Scapin [3], Shneiderman [18], dentre outros. São elas:

- Visibilidade e reconhecimento do estado ou contexto atual, e condição do usuário;

- Projeto estático e minimalista;

- Controle do usuário;

- $\quad$ Flexibilidade e eficiência de uso;

- Prevenção de erros;

- Consistência;

- Compatibilidade com o contexto;

Segundo a autora estas recomendações visam orientar a avaliação de sites Web comerciais, de forma a melhorar a usabilidade, e destinam-se a criadores de conteúdo Web.

Estudos relacionados a experiência do usuário [24], vista como uma consequência do estado interno do usuário (predisposições, expectativas, necessidades, motivação e humor), conduzem a um movimento contrário ao paradigma da usabilidade relacionado a tarefa, ou seja, a tarefa não é mais o objetivo, mas sim a interação em si. Soma-se a isso, as tendências em sistemas de IHC com [24]: novas possibilidades de sensoriamento, como fala ou gestos, mudanças na iniciativa (sistemas pró-ativos), diversificação das interfaces físicas e as mudanças na finalidade da aplicação, para reforçar a importância dos usuários e do contexto de uso. Portanto, quanto aos métodos de avaliação da usabilidade eles parecem estar passando por mudanças no sentido de que não é a tarefa, mas sim a interação e a experiência do usuário que precisam ser avaliadas.

\subsection{Interatividade}

A discussão da interatividade em ambientes virtuais de aprendizagem passa pela disseminação dos ciberespaços, já que estes favorecem, além da manipulação de informações, a criação, o conhecimento e as relações sociais, como caracterizado por Lévy [9]. Desta forma, de acordo com Santos [17], "podemos afirmar que um ambiente virtual é um espaço fecundo de significação onde seres humanos e objetos técnicos interagem potencializando assim, a construção de conhecimentos, logo a aprendizagem" (p.2). 
Os ambientes virtuais de aprendizagem se caracterizam por uma configuração específica em cada curso desenvolvido. Pois, são próprias as informações trocadas através das interfaces, próprias também as interações. Mas, uma coisa é comum em todos, neles, as ações são viabilizadas pelas ferramentas disponibilizadas. Por isso, o ferramental tecnológico disponível em um AVA, intrínseco a estes ambientes, relaciona-se diretamente com as concepções pedagógicas, comunicacionais, práticas e de posturas, que foram pontos de partida para sua criação e premissas para sua utilização. O que defende-se aqui é que estes elementos constitutivos de um AVA, sejam direcionados pela abordagem sócio-interacionista.

Neste sentido, sugere-se a interatividade na educação, do ponto de vista das diversas formas e meios de comunicação, possíveis entre os participantes de um curso online. Silva [20] defende que, a interatividade ocorre quando há comunicação co-criada, em uma dinâmica comunicacional onde emissor e receptor constroem juntos a mensagem.

Silva [20] apresenta ainda, como exemplo dessa abordagem na arte, o parangolé: escultura móvel, do artista plástico Hélio Oiticica que mostra de forma lúdica o que é a interatividade. $\mathrm{O}$ indivíduo veste o parangolé e não apenas o observa, tornando-se co-autor da obra à medida que ele se movimenta correndo ou dançando. Ele vive a arte completando-a e não apenas contemplando. Podemos fazer uma analogia do parangolé com a aprendizagem, através da co-autoria.

Nessa perspectiva, os participantes de um cursos online constroem, criam, modificam, atuam e interagem com os demais participantes, com o conteúdo, assim, o conhecimento é construído e não apenas transmitido. Desta forma, a aprendizagem ocorre através da interação entre sujeito e objeto, ela é baseada na dinâmica interativa, visando à construção do conhecimento.

Em ambientes virtuais de aprendizagem, ferramentas que favoreçam tal interatividade são aquelas que possibilitam além das interações assíncronas (como fóruns e e-mail) e síncronas (como chats), também a colaboração (como wikis), com o uso de blogs, de imagens e animações, que com uma linguagem metafórica, ajudam a caracterizar o ambiente online. $\mathrm{E}$ ainda, quando aos registros escritos, não necessitam ser memorizados (eles estarão disponíveis no ambiente, e sempre será possível voltar a eles).

Nesta perspectiva, a usabilidade e a interatividade estão imbricadas no processo de execução de tarefas em cursos online. Pois, as mesmas podem favorecer ou emperrar o processo ensino-aprendizagem, uma vez que o nível de interação do usuário sofre influências do paradigma que fundamenta tanto as ferramentas disponíveis no sistema Web quanto a proposta metodológica de mediação. Portanto, precisamos estar atentos para o fato de que os paradigmas mecanicistas embasam as interfaces de interação reativas enquanto o paradigma comunicacional emergente está voltado para as interações mútuas nas quais a usabilidade dos sistemas permite a criação e a co-criação através de sistemas abertos e com elementos interdependentes.

\subsection{Usabilidade em Sistemas Web de Ensino a Distância}

Os objetivos dos sistemas para fins educacionais diferem dos sistemas comerciais, pois a utilidade esperada em sistemas para cursos online é diferente do uso de sistemas como ferramenta de produtividade. Tratase de um sistema que viabiliza mediações, interações, colaborações que conduzam os participantes (usuário) a construção de conhecimento.

Alguns pesquisadores [21,7, 23] argumentam que para sistemas educacionais a simples extensão dos métodos de avaliação de IHC originalmente construídos para sistemas Web comerciais não seriam suficientes e propuseram diretrizes específicas que levam em conta objetivos educacionais.

Com o objetivo de integrar aspectos de usabilidade e aprendizado Squires e Preece [21] revisaram as heurísticas propostas por Nielsen, tomando como referência a teoria educacional construtivista. Como resultado eles propuseram um outro conjunto de heurísticas para avaliação de um software educacional.

Também Tselios, Avouris e Komis [23] defendem a hipótese de que critérios tradicionais para avaliar a usabilidade não são totalmente apropriados para o domínio da educação. Os autores citam como exemplo, neste caso, a ocorrência do erro. Por um lado, um requisito básico de usabilidade, voltado para produtividade é prevenir erros dos usuários (apresentado na seção 2.1). Entretanto, a experimentação pode proporcionar oportunidades significativas de aprendizagem. Assim, este último requisito em algumas situações não necessariamente diminui $o$ valor pedagógico do sistema. Pelo contrário, ele pode conduzir a transparência da ferramenta com relação ao conhecimento proposto, possibilitando a expressão de soluções múltiplas.

Jones et al. [7] questionam a relação entre a usabilidade e o processo ensino-aprendizagem. Por outro lado, a pesquisa de Tselios et al. [22], apontou uma correlação entre a usabilidade dos sistemas estudados e o desempenho dos alunos nas tarefas propostas no estudo. 
Amershi et al. [2] também propuseram a separação entre os objetivos de usabilidade e os objetivos pedagógicos em pesquisas conduzidas para avaliação de algoritmos de visualização para fins educacionais.

Trabalhos relacionados que tratam da usabilidade dos softwares que apóiam o ensino (inclusive a distância) e investigam seu impacto nos processos educacionais. Em alguns casos $[4,19,21]$ são sugeridas características pedagógicas relevantes, que quando utilizadas na construção dos sistemas para ensino-aprendizagem podem significar mais do que uma interface de fácil manipulação, mas também uma que favoreça e estimule a participação e interação dos atores envolvidos no processo.

Nessa discussão, a necessidade de investigação dos objetivos de usabilidade no campo das tecnologias da informação e comunicação aplicadas a educação desponta. E os questionamentos apresentados fazem sentido, especialmente quando envolvem fatores motivacionais e de comunicação que favoreçam a interatividade.

\section{Metodologia}

O desenvolvimento da investigação objeto deste trabalho ocorreu com uma metodologia que pretendia, com a análise dos dados obtidos ir além das teorias acerca da avaliação de usabilidade conforme definidas para sistemas Web comerciais.

O tipo de pesquisa utilizada foi a de campo, conforme definida por Inácio [6], a qual não dispensa a pesquisa bibliográfica, mas necessita de instrumentos de coleta de dados. Neste estudo, foi utilizado o método de testes com o usuário (seção 2.1), com questionários como instrumento de investigação. De forma objetiva foram entrevistados usuários, que opinaram sobre ações, tarefas e características dos ambientes virtuais de aprendizagem WebAula e Moodle, no intuito de identificar os principais problemas com a usabilidade e a interatividade nestes ambientes.

Os sujeitos envolvidos na presente pesquisa foram 63 (sessenta e três) estudantes de segundo semestres de cursos de graduação tecnológica presencial na área de informática em uma instituição de ensino superior, os quais, cursavam no período da pesquisa (segundo semestre de 2008) uma disciplina online. Portanto, para esta disciplina a interação e o desenvolvimento dos conteúdos eram através de um sistema Web.

A experiência com a Internet foi decisiva na definição do perfil dos participantes. Outros fatores relevantes foram a experiência com cursos a distância e com os ambientes virtuais em estudo. Para validar os níveis de experiência foi utilizado um questionário pré-teste.

A abordagem metodológica utilizada foi qualiquantitativa, pois além de medições com uso dos indicadores e estatísticas, na pesquisa foram realizadas comparações e interpretações. Os dados obtidos são de origem empírica, com possíveis interferências de valor nos instrumentos e passíveis de interpretações subjetivas [10]. Foram coletados dados subjetivos, através do registro de opiniões, percepções e julgamentos dos usuários quanto a satisfação de uso dos sistemas. Para isso, foi elaborado um questionário de satisfação baseado nos critérios de avaliação de usabilidade propostos pelo Nielsen Norman Group [12], nas heurísticas compiladas por Dias [5] e no questionário proposto por Padilha [13].

$\mathrm{Na}$ análise dos dados, através da estatística descritiva, foram usadas métricas (médias e desvio padrão) que possibilitaram o cruzamento dos dados e a busca por tendências.

\section{Apresentação e Análise dos Resultados}

Tanto o questionário de pré-teste, quanto o questionário de satisfação foram aplicados à usuários do WebAula, 34 participantes, e a usuários do Moodle, 29 participantes, separadamente.

O pré-teste objetivou confirmar o perfil desejado para os participantes, ou seja, bom nível de experiência e frequência no uso da Internet, de forma a evitar dificuldades de utilização não relacionadas aos ambientes virtuais de aprendizagem. Quanto à experiência prévia com estes ambientes foram considerados diferentes níveis de experiência e frequência.

$\mathrm{Na}$ elaboração do questionário de satisfação o objetivo era esclarecer como usuários experientes quanto ao uso da Internet classificavam a usabilidade e interagiam nos ambientes em estudo. Por isso, optou-se pela definição de tarefas comuns em cursos online, as quais foram analisadas pelos participantes, como: navegação básica pelo ambiente, procura por recursos, postagem de mensagens em fóruns.

\subsection{Perfil dos Participantes}

Dentre os 63 usuários que participaram da pesquisa, cerca de 54\% são estudantes enquanto os demais, são estudantes e profissionais (principalmente da área de informática). Quanto à experiência no uso de um site para ensino a distância, $68,2 \%$ indicaram que tratava-se de sua primeira vez. A amostra era constituída, em sua maioria, $73 \%$, por pessoas do sexo masculino.

Esse teste confirmou que os participantes possuíam, 
nos dois casos, níveis médio e alto quanto a experiência com a Internet, neste caso, um mínimo de dois anos de experiência. Exceto por um dos usuários do WebAula que afirmou ter menos de duas semanas de experiência. A frequência de uso da Internet, também situou-se entre alta e média nos dois grupos. Neste caso, trata-se de um mínimo de quatro horas por semana, como o tempo que o usuário passa na Internet. Os números que caracterizam o perfil descrito são apresentados nas figuras 2 e 3.

Também foram confirmados diferentes níveis com relação à frequência de uso do site de $\mathrm{EaD}$ pelos participantes. No caso dos usuários do WebAula (figura 2 ), as respostas concentraram-se entre alta, com visitas ao site de $\mathrm{EaD}$ pelo menos algumas vezes por semana ou diariamente, e média (cerca de 56\%), com visitas ao site de EaD algumas vezes por mês. Apenas 2 (cerca de 6\%) usuários desse sistema afirmaram ter nível baixo, com visitas ao site de menos de uma vez por mês. Os usuários do Moodle (figura 3), de uma forma geral, apresentaram respostas semelhantes aos do WebAula, exceto pelo maior número de usuários com alta frequência de uso do site de $\mathrm{EaD}$ (cerca de 44\%).

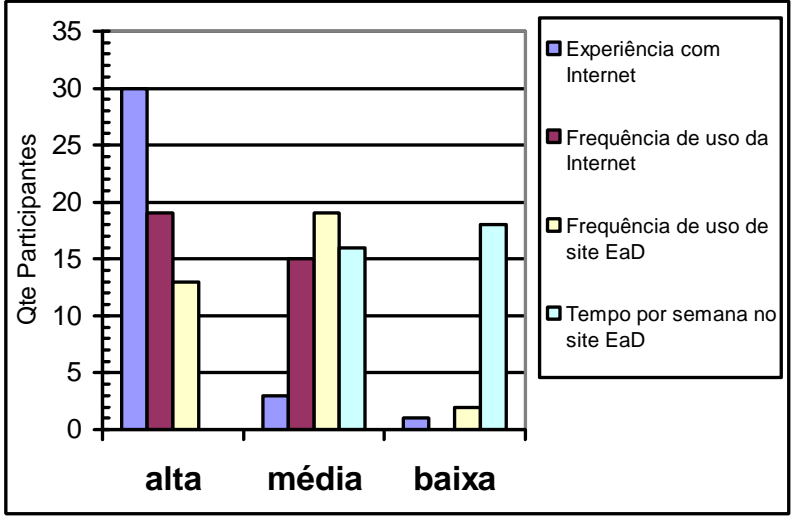

Figura 2. Experiência dos Usuários do WebAula

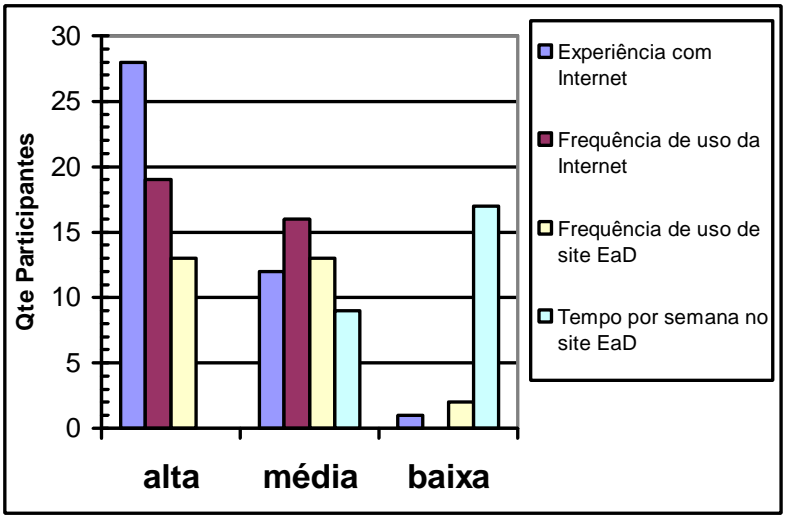

Figura 3. Experiência dos Usuários do Moodle
Entretanto, o tempo por semana no site indicado pelos participantes foi, relativamente, pouco. Os níveis médio e baixo, tiveram predominância nos dois casos, sendo o nível médio, de uma a quatro horas de permanência por semana, e o nível baixo de menos de uma hora por semana. Dos usuários do Moodle (figura 3), 69\% afirmaram permanecer menos de uma hora por semana no site.

\subsection{Teste com os Usuários}

Os questionários foram impressos e entregue aos usuários, para que os mesmos opinassem sobre aspectos de usabilidade e interatividade na execução de tarefas características de cursos online. Ao todos foram 26 questões (indicadores) categorizados da seguinte forma:

- Experiência de navegação no site e aspectos visuais: com 9 indicadores que trataram de aspectos relacionados à apresentação gráfica (agradável e legível); facilidade de navegação através de menus, ícones, links e botões; localização - se os usuários chegam aonde querem, se sabem em que página estão e se o ambiente mantém o padrão Web de cores para links (azul para links não visitados e púrpura para aqueles já visitados), e ainda, liberdade para escolher a seqüência de desenvolvimento dos conteúdos do curso.

- Procura e recursos: com 4 indicadores que trataram de aspectos relacionados à existência de um local para fazer uma procura rápida por um recurso (fóruns, chats, materiais, trabalhos, atividades, anotações, portfólios etc) sem necessitar navegar pelo site; à possibilidade de classificação e à apresentação dos recursos.

- Processo de postagem (e leitura) de mensagens em um fórum: com 5 indicadores que trataram de aspectos relacionados ao processo de postagem de uma mensagem; à facilidade para realizar tarefas como leitura, resposta ou edição das mensagens dos fóruns; disponibilidade, na própria página de resposta, de todas as informações sobre a mensagem sendo respondida, sem precisar memorizar ou voltar à página caso não lembre a pergunta; e das informações necessárias sobre as datas e encadeamento das mensagens já postadas.

- Suporte ao usuário e flexibilidade: $\operatorname{com} 8$ indicadores que trataram de aspectos relacionados à página de ajuda do site - se a mesma á clara e fácil de ser achada; à existência de um local para perguntas freqüentes; à facilidade de localização dos contatos para 
suporte ao ambiente; à disponibilidade de informações sobre os demais participantes; à possibilidade de alteração dos dados pessoais, por exemplo, inclusão de fotos; a navegação mais rápida para usuários mais experientes; à não ocorrência de problemas com bloqueador de pop-up e possibilidade de saída de dados por meio de impressora.

A escala do questionário preenchido pelos participantes que representou uma faixa de -2 a +2 (discordo fortemente, discordo, indeciso, concordo, concordo fortemente). Para fins de análise e estatísticas os valores foram transformados para a faixa de 0 a 4 . Esta escala, portanto, representa o nível de concordância dos participantes quanto aos indicadores analisados, sendo zero forte discordância e quatro forte concordância.

A primeira análise estatística realizada com os dados tabulados foi a média geral em relação aos indicadores avaliados através do questionário de satisfação. A figura 4 mostra a média geral quanto à percepção subjetiva dos usuários em relação aos indicadores de satisfação, que pode ser considerada apenas levemente positiva. Neste caso, a indicação de satisfação para os usuários do WebAula, com média de 2,47 e para os usuários do Moodle, com média de 2,13, foram bem próximas.

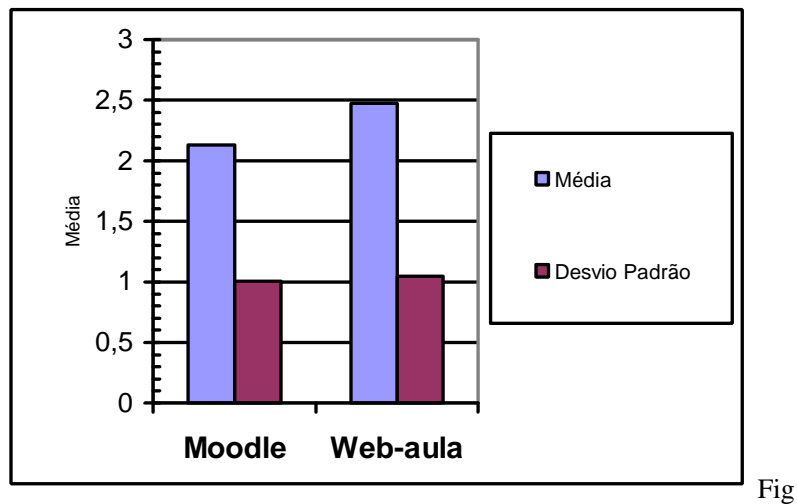

ura 4. Médias Gerais dos Indicadores do Questionário de Satisfação

Em relação ao primeiro aspecto que questionou sobre a experiência de navegação no site e aspectos visuais, os usuários do WebAula indicaram mais satisfação que os usuários do Moodle (tabela 1). Dentre os indicadores avaliados nessa categoria no Moodle representaram maior satisfação para os seus usuários a liberdade para escolher a seqüência de desenvolvimento dos conteúdos do curso (a média deste indicador foi de 2,28 e desvio padrão de 0,92 ) e a prevalência do padrão de cores dos links (média deste indicador 2,62 e desvio padrão 0,78). Entretanto, houve maior insatisfação dos usuários quanto a sua localização no site. Os mesmos indicaram dificuldade para saber em que página estavam e como chegar onde queriam (média 1,41 e desvio 0,82). Para os usuários do
Web-Aula as principais aprovações foram quanto à página principal, que segundo opinião dos usuários oferece percepção de localização no site (média 2,71 e desvio 0,91) e também satisfação quanto a apresentação gráfica, neste caso, indicada como agradável e legível (média 3,09 e desvio 0,79). O indicador que obteve menor média dos usuários do WebAula, para esta categoria foi a liberdade para escolher a seqüência de desenvolvimento dos conteúdos do curso (média de 2,26 e desvio 1,24), o que indicou pouca flexibilidade no desenvolvimento do curso.

$\mathrm{O}$ aspecto procura e recursos, de acordo com os dados coletados, representa um problema no Moodle, já que a média de satisfação foi a menor em relação aos outros indicadores avaliados no próprio Moodle e também aos avaliados pelos usuários do WebAula (tabela 1). Os indicadores com maior insatisfação entre os usuários do Moodle foram a apresentação dos recursos (média 1,55 e desvio 1,02) e a necessidade de navegação pelo site para encontrar os recursos (média 1,62 e desvio $1,05)$. No Web-Aula, a insatisfação maior nesse aspecto, também foi devido a necessidade de navegar pelo site para encontrar os recursos (média 2,09 e desvio 0,93). Em contrapartida, os usuários do WebAula, relativamente, aprovaram a forma como o site apresenta os recursos (médio 2,85 e desvio 1,02).

\begin{tabular}{|l|c|c|}
\multicolumn{1}{|c|}{ Categorias } & Moodle & WebAula \\
\hline $\begin{array}{l}\text { Experiência de navegação } \\
\text { no site e aspectos visuais }\end{array}$ & 2,00 & 2,53 \\
\hline Procura e recursos & 1,92 & 2,52 \\
\hline $\begin{array}{l}\text { Processo de postagem de } \\
\text { mensagens em um fórum }\end{array}$ & 2,46 & 2,67 \\
\hline $\begin{array}{l}\text { Suporte ao usuário e } \\
\text { flexibilidade }\end{array}$ & 2,16 & 2,25 \\
\hline
\end{tabular}

Tabela 1. Médias dos Indicadores Agrupados em Categorias.

$\mathrm{Na}$ avaliação dos indicadores relacionados ao processo de postagem de mensagens em um fórum, também as médias dos indicadores dos usuários do WebAula foram um pouco maiores que do Moodle (tabela 1). A principal insatisfação dos usuários do Moodle foi em relação a disponibilidade, na própria página de resposta da mensagem de informações, sem que seja necessário voltar a página, caso o usuário não se recorde do texto da mensagem sendo respondida (média 2,21 e desvio 0,90). Tanto no Moodle como no WebAula (médias 2,72 e 2,94 e desvios 0,92 e 0,81, respectivamente), o indicador que representou maior satisfação dos usuários nessa categoria foi a 
disponibilidade das informações sobre as datas das mensagens já postadas.

Na categoria de suporte ao usuário e flexibilidade, as avaliações dos indicadores pelos usuários do Moodle e pelos usuários do WebAula tiveram valores de médias bem próximos (tabela 1). No caso do Moodle o indicador que representou maior insatisfação foi quanto à existência de uma página de ajuda ao site, neste caso, apontada como difícil de ser encontrada (média 1,72 e desvio 0,88). O indicador com maior satisfação para os usuário do Moodle, nesta categoria, foi a possibilidade de alteração dos dados pessoais, por exemplo, inclusão de fotos (média 3,00 e desvio 0,96). No WebAula, os indicadores de maior e menor satisfação foram, respectivamente, a possibilidade da saída de dados por meio de impressora (média 2,76 e desvio 0,74) e os problemas com bloqueador de pop-up (média 1,44 e desvio 1,24).

Portanto, os resultados apontam alguns problemas de usabilidade nos dois sistemas, em especial aqueles relacionados à navegação e arquitetura da informação, no caso do Moodle o problema é a localização, no WebAula são os pop-ups e o uso de animações Flash no ambiente, as quais comprometem o tempo de download. O suporte ao usuário também foi um tópico que deixou a desejar nos dois casos: no Moodle os usuários não encontraram facilmente uma página de ajuda ao site, nem os contatos com o suporte ao sistema. Enquanto no WebAula os usuários consideraram pouca a flexibilidade para personalização e a liberdade para escolher a sequência de desenvolvimento dos conteúdos do curso.

Possíveis motivos para que o Moodle tenha apresentado problemas de navegabilidade estão na estrutura do site, que no caso, não atendeu as expectativas dos usuários. Um aspecto que acentuam esse problema é o uso de rótulos para nome dos links, eles devem fazer sentido para os usuários, de forma que comuniquem ao usuário exatamente o que ele encontrará ao clicar. Por outro lado, os usuários indicaram que o padrão de cores para os links é mantido no Moodle, isso ajuda o usuário a identificar o que é clicável.

O WebAula foi avaliado como um ambiente simples e agradável, tendo como seu maior índice de aprovação o aspecto visual, porém deixa a desejar em aspectos de praticidade na interação do usuário com o sistema.

\subsection{Comentários dos usuários}

Na análise dos sistemas, no questionário de satisfação, os participantes opinaram sobre a execução de tarefas típicas em cursos online e também registraram de forma mais livre, suas percepções através de questões abertas. A coleta de comentários, expressos voluntariamente pelos usuários forneceu indícios sobre a usabilidade dos sistemas, mas principalmente sobre a interatividade no desenvolvimento dos cursos nos ambiente virtuais de aprendizagem.

A seguir são apresentados alguns comentários presentes nos questionários, eles foram selecionados pela relevância, por representarem opiniões de alguns usuários:

Comentários relacionados ao WebAula quanto ao que o usuário mais gostou no site:

"Layout, a facilidade de uso."

"Dos fóruns."

"Da interação do grupo."

Comentários relacionados ao WebAula quanto ao que o usuário acha que pode ser melhorado no site:

"Não concordo em ter que liberar um recurso do bowser, ou seja, liberar qualquer pop-up deste site."

"Ele é muito pesado, passo muito tempo para poder abrí-lo."

"Melhorar a comunicação entre os usuários."

"O conteúdo é pouco, ou nada explicativo. Confuso é quase ineficiente."

"Com uma música ambiente."

"Deixar tudo em uma janela única com abas."

"Poderia haver conteúdos multimídia como vídeoaulas ao invés de textos massantes.”

Comentários relacionados ao Moodle quanto ao que o usuário mais gostou no site:

"A idéia de EaD, mas acho que tem muito o que melhorar na facilidade de navegação."

"A facilidade de interagir com os outros usuários."

Comentários relacionados ao Moodle quanto ao que o usuário acha que pode ser melhorado no site:

"Precisa ser mais organizado no que se refere aos fóruns, tópicos e postagens."

"Péssimo, prefiro o Webaula."

"Site fora do ar."

"Na tela inicial, no momento do login ir direto para acesso que estou vinculada e não me mostrar todos os cursos e ir procurando o que estou realizando."

"Mais recursos gráficos."

"A navegabilidade no sentido de uma melhor localização do conteúdo e assuntos."

"O site poderia conter um pouco de Web 2.0, pois PHP é uma linguagem defasada." "Aplicando novas tecnologias de interação com o usuário."

"Sendo mais dinâmico." 
Os comentários dos usuários, de forma amostral, corroboram com as observações anteriores sobre a importância da relação usabilidade e interatividade. Mostram estudantes ávidos pelas interações possíveis nos ambientes virtuais de aprendizagem. Sugerem inclusive tecnologias mais atuais que proporcionariam atratividade e favoreceriam mais a interatividade nos sistemas.

\section{Considerações}

Apesar da usabilidade não ser a questão mais importante em um ambiente Web para educação a distância no que se refere ao processo ensinoaprendizagem, ela pode determinar ou ser o estímulo inicial e continuado para o participante, especialmente para as interações no ambiente. Apesar de não impedir o uso do sistema, a falta de usabilidade pode dificultar e conseqüentemente causar desestímulo, com usuários permanentemente exitantes, inseguros e desorientados.

Por isso, identificar quais problemas de usabilidade são críticos em sistemas Web para ensino a distância, podem indicar, para desenvolvedores, projetistas, e também para equipes de produção de material didático, alguns problemas, nos quais uma atenção especial pode ser concentrada.

Segundo Nielsen and Loranger [12] as maiores dificuldade impostas aos usuários, e que portanto, representam uma classificação de gravidade são, principalmente, nesta ordem: pesquisa, arquitetura da informação, legibilidade e conteúdo.

Os problemas acima citados, especificados pela navegação, links, nome de categorias, pop-ups e procura, foram também dificuldades apontadas pelos usuários nesta avaliação dos sistemas Moodle e WebAula.

Os aspectos relacionados ao conteúdo do site, que neste caso, referem-se aos assuntos de cada disciplina representaram um tópico fora do escopo do presente estudo. Isto porque os cursos disponibilizados no WebAula que foram objeto de avaliação, possuem conteúdo elaborado por uma equipe de produção multidisciplinar. Enquanto os curso avaliadas do Moodle possuem conteúdo elaborado pelos próprios professores da disciplina.

Apesar de não ter sido avaliado diretamente, os resultados podem ter sido influenciados pelas diferentes características quanto a produção do material e ao design instrucional em cada um dos ambientes, e pelas configurações e opções disponibilizadas para os usuários participantes do presente estudo.

A impossibilidade de realizar as atividades, o fato de ter suas ações limitadas, a necessidade de memorização, dentre outras dificuldades, são problemas graves no contexto dos cursos online. Especificamente no escopo do presente estudo houve indicação de que, mesmo usuários experientes não conseguiam superar várias dificuldades.

Portanto, a usabilidade e a interatividade foram analisadas como aspectos de qualidade dos AVA, quando utilizados por estudantes de cursos de graduação em informática. Percebeu-se entretanto, que um questionário, usado de forma isolada é relativamente pouco eficiente para avaliar a usabilidade e a interatividade de um sistema Web para cursos online. O método adotado, portanto, possibilita apenas a obtenção de informações quanto a um grau de satisfação relativo dos estudantes. Por um lado, ainda insipiente para afirmações mais precisas, por outro, entretanto, contribui para um diagnóstico inicial, que aponta caminhos para possíveis melhorias, válidos neste contexto, especialmente no design de curso. Assim, testes com usuários que envolvam também a observação de usuários em ação, quando realizando tarefas específicas, propiciem resultados mais precisos.

A partir das percepções obtidas neste trabalho, os estudos terão continuidade, na investigação da hipótese de que a interatividade é prejudicada pela existência de problemas de usabilidade, que impedem uma maior e melhor utilização pelos usuários dos sistemas Web para cursos online.

\section{Referências}

[1] ACM SIGCHI - Association for Computing Machinery Special Interest Group on ComputerHuman Interaction. Curricula for humancomputer interaction. Technical report, 1992.

[2] S. Amershi, et. al. Pedagogy and usability in interactive algorithm visualizations: designing and evaluating CIspace. Interacting with Computers, New York, USA, v. 20, n. 1, p. 64-96, jan. 2008.

[3] J. M. C. Bastien, D. L. Scapin. Ergonomic Criteria for the Evaluation of Human-Computer Interfaces. (Relatório de Pesquisa No. 156). INRIA Institut National de Recherche en Informatique et en Automatique, Rocquencourt, França. 1993.

[4] A. H. P. Carvalho, I. T. Costa,. A usabilidade e os sites de educação a distância. Revista Paidéia, v. 1, n. 1, UNIMES - SP. Disponível em: <http://revistapaideia.unimesvirtual.com.br/>. Acesso em : 15 set 2008. 
[5] C. Dias. Usabilidade na WEB: Criando portais mais acessíveis. Alta Books. 2003.

[6] G. Inácio Filho. Planejamento da pesquisa. In: _. Monografia na universidade.5. ed. Campinas SP: Papirus, 1995 , cap. 3, p. 49-45.

[7] A. Jones et. al. Contexts for evaluating educational software. Interacting with Computers, Cambridge, UK, v. 11, n. 5, p. 499-516, may. 1999.

[8] A. Laville. L'ergonomie. 5. ed. PUF coll.QSJ: 1993.

[9] P. Lévy. A inteligência coletiva: por uma antropologia do ciberespaço. 3. ed. Loyola. São Paulo: 2000.

[10] A. C. Meurer, T. M. Hetkowski. Ensaio sobre Metodologia de Pesquisa em educação. Educação na Faculdade de Educação - FACED/UFBA. 2008.

[11] J. Nielsen. Usability Engineering, Academic Press, Cambridge, MA, 2003.

[12] J. Nielsen, H. Loranger. Usabilidade na Web: projetando websites com qualidade. Tradução Edson Furmankiewicz \& Carlos Schafranski, Docware Traduções Técnicas. Rio de Janeiro: Elsevier, 2007.

[13] A. V. Padilha. Usabilidade na Web: uma proposta de questionário para avaliação do grau de satisfação de usuários do comércio eletrônico. 2004. 103 f. Dissertação (Mestrado) - Programa de Pós-Graduação em Ciência da Computação, Universidade Federal de Santa Catarina, 2004.

[14] J. Piaget. Biologia e Conhecimento. 2. ed. São Paulo: Vozes, 1996.

[15] A. F. T. Primo, M. B. F. Cassol. Explorando o conceito de interatividade: definições $\mathbf{e}$ taxonomias. 2000. Disponível em: <http://www.psico.ufrgs.br/ aprimo/pb/pgie.htm >. Acesso em: 16 nov. 2008.

[16] H. V. Rocha, M. C. C. Baranauskas. Design e Avaliação de Interfaces Humano-Computador. Campinas: NIED/UNICAMP, 2003.

[17] E. O. Santos. Ambientes virtuais de aprendizagem: por autorias livres, plurais e gratuitas. Revista da FAEEBA: Educação e Contemporaneidade, Salvador, v. 11, n. 18, p. 425-435, jul/dez. 2002.

[18] B. Shneiderman, B. Designing the user interface: strategies for effective human-computer interaction.3.ed.Reading, Mass.: Addison-Wesley, 1998.

[19] C. R. O. SIlva. MAEP: um método ergopedagógico interativo de avaliação para produtos educacionais informatizados. Florianópolis, 2002. 224f. Tese (Doutorado em Engenharia de Produção e Sistemas) - Programa de Pós-Graduação em Engenharia de Produção, UFSC, 2002.

[20] M. Silva. Sala de aula interativa: a educação presencial e a distância em sintonia com a era digital e com a cidadania. Boletim Técnico do Senac, Rio de Jnaeiro, v. 27, n. 2, mai/ago. 2001.

[21] D. Squires, J. Preece, Predicting quality in educational software: Evaluating for learning, usability and the synergy between them. Interacting with Computers, v.11, p. 467-483, USA, 1999.

[22] N. Tselios et al. Evaluation of distance-learning environments: impact of usability on student performance. International Journal of Educational Telecommunications, GR,v.7,n.4,p.355-378.2001.

[23] N. Tselios, N. Avouris, V. Komis. The effective combination of hybrid usability methods in evaluating educational applications ICT: issues and challenges. ACM Education and Information Technologies, Hingham, MA, USA, v. 13, n. 1, p. 55-76. mar. 2008.

[24] R. Poppe, R. Rienks, and B. van Dijk. Evaluating the Future of HCI:Challenges for the Evaluation of Emerging Applications. Artificial Intelligence for Human Computing, LNAI 4451, pp. 234-250, 2007. 